\title{
The Role of Motivation in Enhancing Employees' Creativity: A Literature Review
}

\author{
Maryam Hashem¹, David Gallear ${ }^{1}$, and Tillal Eldabi ${ }^{2}$ \\ ${ }^{1}$ College of Business, Arts and Social Sciences, Brunel University London \\ ${ }^{2}$ College of Business \& Finance, Ahlia University, Bahrain
}

\section{Abstract}

Organizations from different industries worldwide focus their efforts and budgets to enhance employees' creativity which is widely perceived as a major success ingredient in today's challenging business environment. Consequently, practitioners and managers establish reward systems to enhance employees' creativity. However, the literature presents opposing views pertaining to the relationship between rewards and employees creativity, such that some scholars find it important to be intrinsically motivated to be creative whereby others find extrinsic motivation (e.g. rewards) to be important to enhance creativity. This paper aims to provide a comprehensive literature

Corresponding Author:

Maryam Hashem

Maryam.hashem@brunel.ac.uk

Received: 22 July 2019

Accepted: 16 September 2019

Published: 19 September 2019

Publishing services provided by

Knowledge E

(c) Maryam Hashem et al. This article is distributed under the terms of the

Attribution License, which

permits unrestricted use and redistribution provided that the original author and source are credited.

Selection and Peer-review under the responsibility of the PwR Symposium Conference Committee.

\section{G OPEN ACCESS} review by presenting prominent theories addressing the role of intrinsic and extrinsic motivation in enhancing employees' creativity. It then highlights the research questions intended to be investigated and finally presents the context of proposed empirical research.

Keywords: creativity, intrinsic motivation, extrinsic motivation, rewards

\section{Introduction}

The ultimate goal of most organizations from different industries across the globe is to achieve sustainability and long term success. In today's global business environment, obtaining competitive advantage and achieving long term success has become a challenging goal for organizations. Accordingly, organizations direct tremendous efforts and budgets to foster employees' creativity. Understanding the ways of enhancing employees creativity is believed to be fruitful for organizations success as well as for the economic growth of a country as stated by the Organization of Economic Cooperation and Development (OECD, 2010), such that the innovation of a country branches from the innovation of its organizations which constitute of people, therefore, enhancing employees creativity is key. In the same context, fostering employees' creativity has its own set of benefits to the employees themselves, especially that the mechanisms used to enhance creativity could include rewards and incentives for creative employees. 
A considerable number of studies have shed light on the antecedents and conditions that hinder or promote employees' creativity (Amabile, Henessey and Grossman, 1986; Woodman, Sawyer and Griffin, 1993; George and Zhou, 2002; Baer, Oldham and Cummings, 2003). The main aim of those studies was to investigate the relationship between contextual factors and employees creativity to advance the understanding as well as to outline the conditions under which those factors are instrumental or detrimental to employees' creativity. A number of scholars have argued that intrinsic motivation (i.e. an individual is engaged in an activity for the sake of the activity itself as he/she finds it interesting and exciting) is an important ingredient to boost employees' creativity (Amabile, 1996; Shalley and Oldham, 1997). In light of this view, managers should consider providing employees with opportunities to gain intrinsic rewards such as engaging employees in challenging and stimulating jobs (Hackman and Oldham, 1980).

Despite the literatures suggestion of using intrinsic rewards, managers continue to use extrinsic rewards (e.g. monetary incentives) (Fairbank and Williams, 2001). In a similar vein, a group of scholars argue that the use extrinsic rewards will enhance employees' creative performance (Eisenberger, 1992), whereas another group of scholars argue that the use of extrinsic rewards will diminish employees' creativity (Amabile, 1996). It is unfortunate that the direction of extrinsic rewards effects on employees creativity has a little agreement among scholars (Amabile, 1996). This inconsistency in research findings provide an opportunity to investigate the specific conditions under which rewards have negative, positive or neutral effects on employees creativity (Shalley and Zhou, 2003; Anderson, Potocnik and Zhou, 2014). This will not only help us understand different conditions but will also assist managers in adopting a selective rewarding strategy in respect to creativity.

Consequently, the purpose of this paper is to provide a literature review of the relationship between rewards and employees' creativity and to highlight the research gap. It aims at presenting the prominent theories and frameworks that addresses the relationship as well as the research findings of distinct groups of scholars. The paper is structured as follows: Section 1 provides an introduction to the topic, the objective of the research and it highlights the key beneficiaries of the study. Section 2 provides the theoretical background by presenting the prominent theories and frameworks in the literature. Section 3 provides a critique to the existing literature and identifies the research questions. Section 4 presents the research context. Section 5 presents the conclusions and suggested future work. 


\section{Theoretical Background}

The body of research on employee creativity and work motivation have progressed massively since 1988 when the first creativity model was introduced by Amabile, and since Porter and Lawler first discovered work motivation in 1968. It is noteworthy that this field have received a considerable attention from scholars given the importance of work motivation in fostering employees' creativity (Deci and Ryan 1985; Amabile 1996), and the fundamental role of employees' creativity in gaining competitive advantage and fostering organizational survival (Zhou and Shalley, 2003; Anderson, De Dreu, $\&$ Nijstad, 2004). Although the scholarly progress and yielded results are significant thus far, the need for further advancement in the subject matter is inevitable. The relationship between employees' motivation and creativity is not well defined yet in the literature, such that many studies yielded different results on whether rewarding employees will lead to enhanced creativity or not (Eisenberger \& Cameron, 1996). From this ground, this section aims to provide a comprehensive review of the literature on employees' creativity, intrinsic and extrinsic motivation and other related variables such as employees individual traits. The following paragraphs will further define the intended variables.

Creativity is defined early in the literature as the production of original and useful ideas (Amabile, 1996). It is suggested that creative ideas could be generated from employees at any level of the organization, in any job and not necessarily a job that demands creativity (Majdar, Oldham, and Pratt, 2002; Nonaka, 1991). As pointed in the literature, creativity can occur at an individual, team and organizational level or at more than one of these levels combined (Anderson, Potočnik and Zhou, 2014). Creativity is often viewed as the first step of innovation, since creativity is centered on idea generation whereas innovation is centered on idea implementation (Amabile, 1996; Mumford and Gustafson, 1988). This paper will focus on employees' individual creativity only and not organizational innovation as this study intends to address the relationship at an individual level and not on an organizational level.

Being motivated is defined as being moved to do a certain activity, a person who is energized to do a certain task is considered motivated whereas a person who is not inspired to act is considered unmotivated (Ryan and Deci, 2000). The discovery of intrinsic and extrinsic work motivation goes back to Porter and Lawler's proposed model in 1968. Intrinsic motivation is defined as the motivation to do an activity because it is interesting and gives spontaneous satisfaction. Whereas extrinsic motivation is defined as the motivation to do an activity because of a separate consequence such as verbal 
or tangible rewards. In the case of extrinsic motivation, the satisfaction is obtained from the consequences (e.g. rewards) rather than from the activity itself.

The following table presents prominent studies in the literature that have addressed the relationship between employees' creativity and motivation.

TABLE 1: Prominent studies in the literature of creativity and Motivation (Source: Journal Articles).

\section{Author, year and Contribution name of theory}

Deci and Ryan 1985. (Cognitive evaluation theory)

This theory suggests that contextual factors that affect intrinsic motivation has two functions "informational" or "controlling". When it is informational, it positively affects intrinsic motivation and hence creativity. When it is controlling it negatively affects intrinsic motivation and hence creativity. According to the cognitive evaluation theory, people need to feel autonomous and competent, when individuals feel competent and self-determining, they will experience high level of intrinsic motivation toward a task. Therefore contextual factors that promote the feeling of autonomy and competence enhance intrinsic motivation and hence creativity, whereas factors that diminish these feelings undermine intrinsic motivation and creativity respectively.
Baer, Oldham and This study examines some contextual cummings, 2003. factors that could have informational or (it refers to Cognitive evaluation theory) controlling effect on employees creativity as suggested by the cognitive evaluation theory in 1985. According to this study it is mentioned that the link between intrinsic motivation and creativity is positive as agreed by scholars (accepted wisdom). It suggests that extrinsic reward-creativity relationship is inconsistent because of the link between extrinsic rewards and intrinsic motivation. There are conditions (contextual factors) such as job complexity and cognitive style, under which extrinsic rewards boost intrinsic motivation or not, which in terns affects creativity. This study found the following results: o Adaptors in simple jobs are more creative when offered extrinsic rewards. o Innovators in simple jobs are less creative when offered extrinsic rewards. o Adaptors in complex jobs are less creative when offered extrinsic rewards. o Innovators in complex jobs are neutrally creative when offered extrinsic rewards.
Scope for further advancement in relation to this paper

This theory was tested on laboratory experiments and not in organizational settings, which leads to the issue of external validity of the research findings since the laboratory environment includes participants who are often not full time employees and hence it cannot constitute a real work environment (Shalley and Zhou, 2003). Second, it assumes that being motivated by extrinsic rewards contingency rather than the work itself is detrimental to intrinsic motivation and hence creativity, without considering that people actually work to earn money and therefore monetary rewards should be an appealing motive. Moreover, this theory does not provide clear directions and conditions for managers under which extrinsic rewards should be used. It provides an opportunity for future research to investigate the relationship between rewards and creativity in organizational settings as well as to test conditions that could have "informational effect" to intrinsic motivation.

Although it is argued in this study that extrinsic rewards affect creativity through effects on intrinsic motivation. intrinsic motivation is not measured directly in this study, so it's not clear if the effects of reward, job complexity and cognitive style are mediated by intrinsic motivation 


\begin{tabular}{|c|c|}
\hline $\begin{array}{l}\text { Author, year and } \\
\text { name of theory }\end{array}$ & Contribution \\
\hline $\begin{array}{l}\text { Janssen and } \\
\text { Yperen, } 2004 . \\
\text { (refers to the } \\
\text { achievement goal } \\
\text { theory, Dweck } \\
\text { 1986) }\end{array}$ & $\begin{array}{l}\text { In this study the researchers examined } \\
\text { the relationship between goal } \\
\text { orientations and employees creativity, } \\
\text { Goal orientations are important } \\
\text { contextual factors to be considered to } \\
\text { further understand the relationship } \\
\text { between rewards and employees } \\
\text { creativity. This study proposed and } \\
\text { found that individuals having a mastery } \\
\text { goal orientation are positively related to } \\
\text { innovative job performance and that } \\
\text { individuals with performance orientation } \\
\text { are negatively related to innovative job } \\
\text { performance. }\end{array}$ \\
\hline
\end{tabular}

Theresa Amabile In the dynamic componential model, a and Micheal G. Pratt, 2016 (Dynamic componential model for creativity and innovation) significant modification for the role of intrinsic and extrinsic motivation has been suggested as an advancement to the componential model for creativity and innovation developed in 1988. The model acknowledges that extrinsic motivation has a positive role in the creativity process, the model suggests that some kinds of extrinsic motivations have a harmonious effect with intrinsic motivation to stimulate creativity, the process is termed "motivational synergy" (Amabile,1993). This modification was drawn from the cognitive evaluation theory (Deci and Ryan, 1985), it suggests that "informational" extrinsic motivators (which gives people information that allows them to build their competence) are more supportive of intrinsic motivation than "controlling" extrinsic motivators (which makes people feel controlled by an external force). It is noteworthy that this recent study have shed the light and developed an emphasize on the importance of extrinsic motivation, which did not warrant attention in previous research (Amabile, 1988)
Scope for further advancement in relation to this paper

the results of this study cannot be generalized since the sample used consisted of 170 employees from a Dutch firm that is an energy supplier. The sample consisted of employees of a lower level from an industrial organization only. Also, innovative job performance was a dependent variable in this study and creativity was not, therefore the result of this study cannot be generalized on the relationship between goal orientations and creativity. Although Mastery orientation was found to be positively related to innovative behavior, the measure that was used in this study included both idea generation and idea implementation (Anderson et al., 2014).

The dynamic componential model is however a theoretical model which is not supported empirically yet. In addition, people might react differently to different motivators depending on their personal orientations and the way they perceive those motivators and therefore the assumptions of the model cannot be generalized. It sets the ground for future research opportunities to investigate specific personal orientations e.g. goal orientations as stable personality trait in relation to employees creativity.

\section{Research Questions}

Although researchers have devoted effort to studying the relationship between those variables (rewards, employee's creativity and intrinsic motivation) as illustrated in the previous section, it is obvious that the studies that have been conducted have produced contradictory results. In addition, the results of those studies cannot be generalized 
either because of the lack of empirical testing or due to the type and relevance of the samples used or because of the differences in the situation and context. Moreover, the comprehension of the relationship between variables is affected by other variables that may act as either mediators or moderators. The following lines will shed the light on the gap found in the existing literature from which this research questions set's its ground.

When studying the relationship between rewards and creativity, researchers arrived at different results. The paradox of rewards was highlighted multiple times in the literature as a challenging unanswered question that entails future research attention(Zhou and Shalley, 2003; Anderson et al., 2014). Some scholars argue that the use of extrinsic rewards leads to diminishing creativity via undermining intrinsic motivation (Amabile, 1996). This view is proved empirically, for instance, Amabile, Hennessey and Grossman (1986) found in a laboratory study that when participants agree to work on a certain task in order to receive a reward (contracted for reward), there is a negative effect on creativity. This is in addition to other empicial studies that demonstrate the negative effect of rewards on creativity (Kruglanski, friedman and Zeevi, 1971). On the other hand, other scholars suggest that the use of extrinsic rewards enhances creative performance (Eisenberger, 1992). Researchers found that rewards can have informational value which can be used to encourage creativity (Eisenberger \& Selbst, 1994; Eisenberger \& Armeli, 1997). This position was also supported empirically (Eisenberger, Armeli \& Prets, 1998; Eisenberger \& Rhoades, 2001). There are also studies that show that extrinsic rewards only have a negligible effects on creativity (Hennessey, 1989; Joussemet \& Koestner, 1999). Considering the above mixed results in the literature, there is a subsequent need to investigate specific conditions under which extrinsic, contingent rewards have positive, negative or neutral effects on creativity (Eisenberger \& Cameron, 1996).

The use of various moderators and mediators to study the relationship between rewards and creativity is not uncommon in the literature (Deci and Ryan 1985, George and Zhou, 2002; Baer, Oldhum and Cummings, 2003; Janssen and Yperen, 2004; Eisenberger and Aselage, 2009. There are potential important moderators that were hardly investigated and requires future research attention (Anderson et al., 2014). With regards to mediators, in 2004, Shalley, Oldhum and Zhou conducted a literature review on the effects of personal and contextual characteristics on creativity. They found that many studies were consistent with the argument that contextual factors affect creativity via their effects on individuals' intrinsic motivation, yet few studies actually measured intrinsic motivation and tested whether it empirically mediates the context-creativity relation (Zhou \& Shalley, 2003). With respect to moderators, many studies used different moderators to understand the relationship between creativity and other contextual 
factors, for instance, perceived recognition and reward for creative performance and clarity of feelings were used moderators (George and Zhou, 2002), Job autonomy and time pressure (Wu, Parker and De Jong, 2014). The only moderators used to study the relationship between creativity and rewards was employee job complexity and cognitive style (Baer, Oldhum and Cummings, 2003). In this study it is intended to study goal orientations as moderators of the relationship between rewards and creativity. The reasons underlying the selection of this moderator is first the scarcity of using moderators to study the relationship between rewards and creativity. Second is the usefulness of such moderator to explain the relationship, since the direct relationship between goal orientations (mastery orientation and performance orientation) and innovative performance was previously studied in the literature (Janssen and Yperen, 2004) yielding a negative relationship for a performance orientation and a positive relationship for a mastery orientation. Thirdly, in spite of the results pertaining to goal orientations and innovative job performance, there is still a need for further research to disclose whether the relationship is with creativity or innovation, because (innovative performance) as a used measure does not distinguish between idea generation and idea implementation (Anderson et al., 2014).

\subsection{The research gap}

This subsection summarizes the gap found in the literature which is intended to be addressed through this study.

\subsubsection{The Paradox of reward:}

Some scholars argue that the use of extrinsic rewards leads to diminishing creativity via undermining intrinsic motivation (Amabile, 1996). This view is proved empirically (Amabile, Hennessey and Grossman, 1986, Kruglanski, friedman and Zeevi, 1971). While other scholars suggest that the use of extrinsic rewards enhances creative performance (Eisenberger, 1992). Rewards can have informational value which can be used to encourage creativity (Eisenberger \& Selbst, 1994; Eisenberger \& Armeli, 1997). The later position was also supported empirically (Eisenberger, Armeli \& Prets, 1998; Eisenberger \& Rhoades, 2001). 


\subsubsection{The use of moderators:}

There are potential important moderators that were hardly investigated and require future research attention (Anderson et al., 2014), goal orientations are part of them. Although goal orientations were previously studied in the literature (Janssen and Yperen, 2004), there is still a need for further research to disclose whether the relationship refers to employees creativity or innovation, because (innovative performance) as a used measure does not distinguish between idea generation and idea implementation (Anderson et al., 2014).

\subsubsection{Intrinsic motivation as a mediator:}

Many studies were consistent with the argument that contextual factors affect creativity via their effects on individuals' intrinsic motivation, yet few studies actually measured intrinsic motivation and tested whether it empirically mediates the context-creativity relation (Zhou \& Shalley, 2003).

The result of this study aims to address this gap in the literature and contribute to goal orientation theory by demonstrating the link between rewards and employees creativity moderated by goal orientations (mastery and performance) and mediated by intrinsic motivation.

This review leads to the following proposed research questions:

1. How does intrinsic motivation mediate the relationship between rewards and employee creativity?

2. What is the relationship between rewards and employees creativity for employees with mastery goal orientation? (Positive/negative)

3. What is the relationship between rewards and employees creativity for employees with Performance goal orientation? (Positive/negative)

\section{Research Context}

In this research it is aimed to study creativity and work motivation in the kingdom of Bahrain. Creativity and innovation have recently received a major attention of Gulf Cooperation Council (GCC) countries. GCC countries are looking to evolve in an innovationdriven economy as those countries recognize the essential role of innovation in creating future economic wealth (Gackstatter, Kotzemir and Meissner, 2014). 
According to the global innovation index for the year 2018, Bahrain's GII rank is 72 which gives Bahrain the last rank among all GCC countries for the same year as shown in Figure 1,Whereas United Arab Emirates is ranked 38 globally and the first among GCC countries from the 130 innovative countries' index.

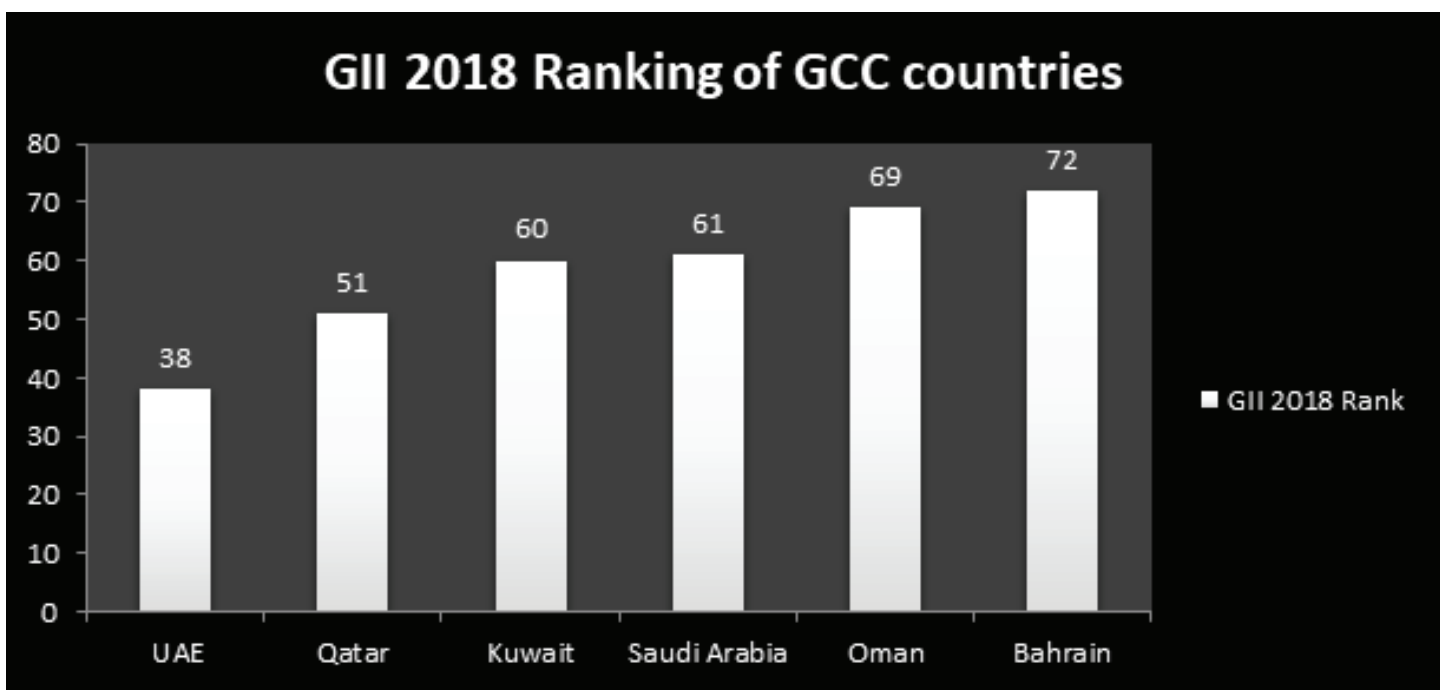

Figure 1: Global Innovation Index ranking of GCC countries in 2018 (Source: Adopted from Global Innovation Index, 2018).

Figure 2. shows the components of the global innovation index, namely (institutions, human capital and research, infrastructure, market sophistication, business sophistication, knowledge and technology outputs and creative outputs), it serves to compare the global ranking of the GCC countries in the year 2018. As illustrated in Figure 2., Bahrain is ranked the last in (institutions innovation) whereas UAE takes the first place in this category. According to GIl, the institutions pillar comprises of political, regulatory and business environments, in which Bahrain suffers from income group weakness.

Not only did Bahrain score poorly compared to its neighbor GCC countries, but also Bahrain's innovation ranking has been gradually deferring compared to its own global ranking in the previous years as shown in Figure 3.

Bahrain's delayed global rank for innovation calls for further enhancement, from which this study bases its ground aiming to discover clear links leading to employee's creativity and innovation in Bahrain. Therefore, this study aims to demonstrate the relationship between employee's motivation and their creativity and innovation in the work place by conducting an empirical study in Bahrain. Clarifying the ties of this relationship is capable of guiding practitioners and managers in their selection of the right form of motivation to enhance the creativity of their employees which consequently leads to enhancing Bahrain's global innovation index ranking. 


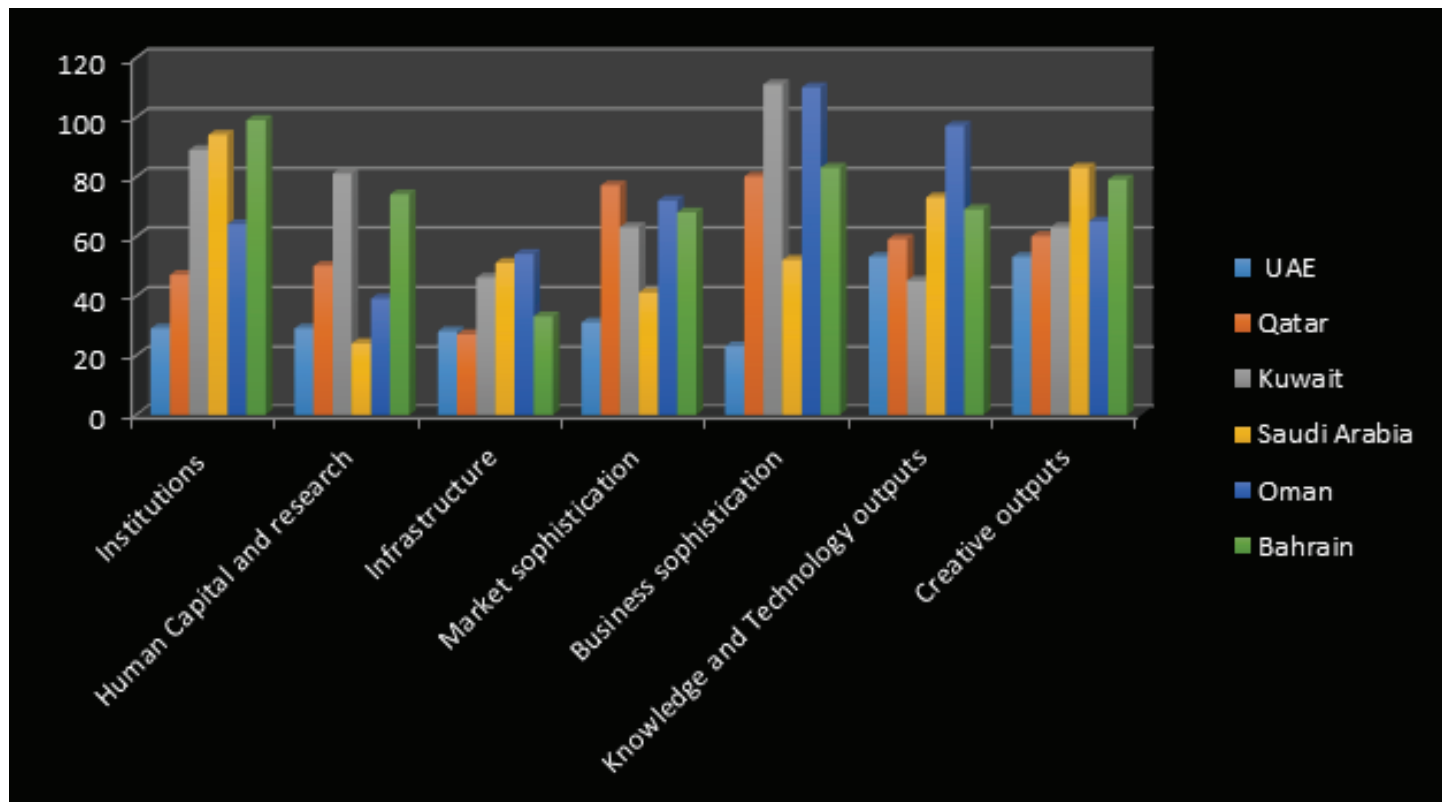

Figure 2: GCC countries global innovation ranking breakdown in 2018 (Source: Adopted from global innovation index, 2018).

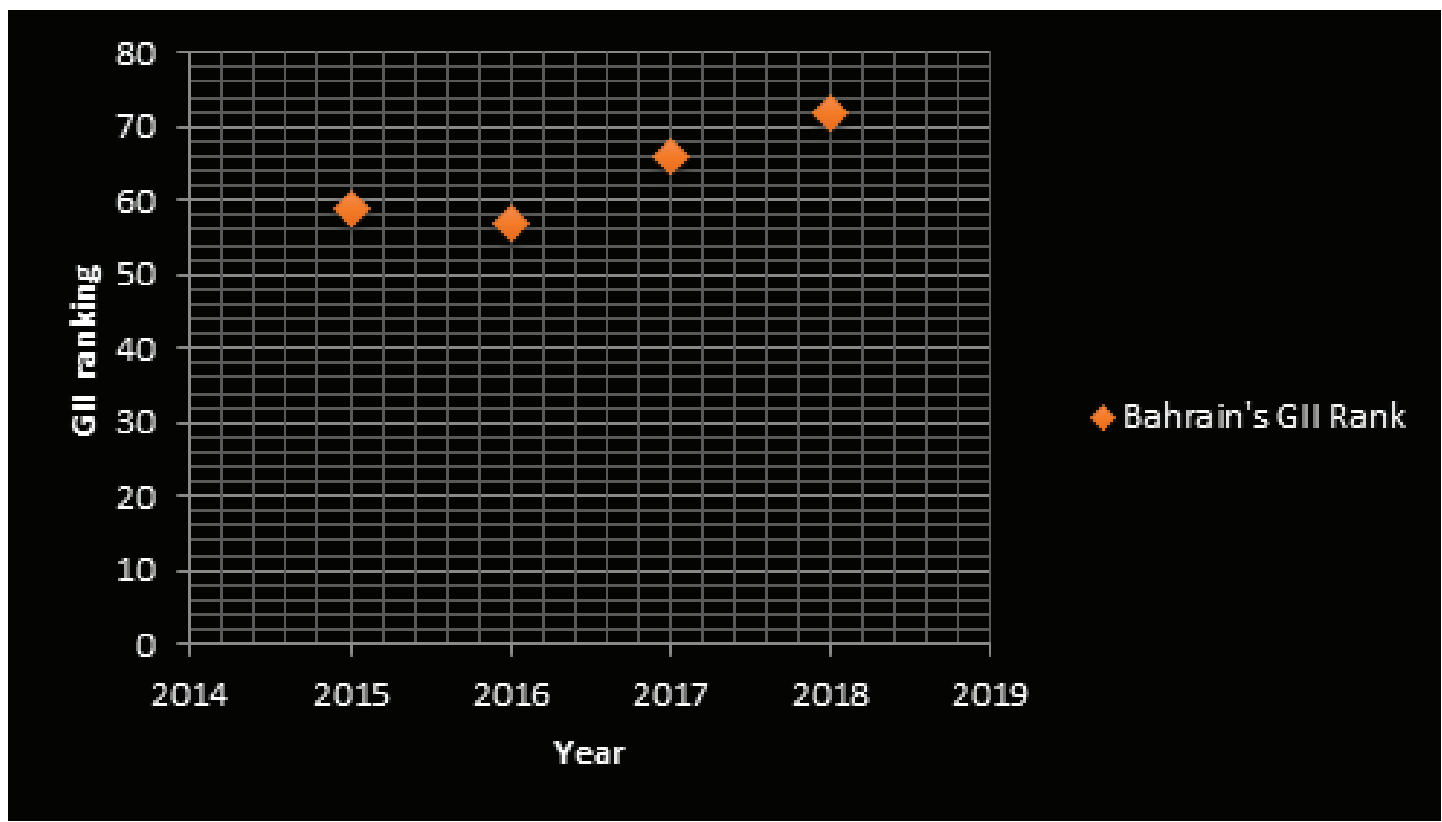

Figure 3: Bahrain's Global Innovation index ranking 2015-2018 (Source: Adopted from global innovation index, 2015-2018).

\section{Conclusion}

This paper had provided a comprehensive review of the literature on creativity and work motivation. Key theories in the field of employees' creativity and work motivation were presented. It established the background of the research topic by demonstrating clear definitions on the intended variables to be studied in this research such as creativity, 
intrinsic and extrinsic motivation. A critique of the existing literature was highlighted from which the research questions were initiated, aiming to build on the previous findings and to establish new results that address those gaps. Finally, the research context was presented.

\section{References}

[1] Amabile, T. M. 1988, 'A model of creativity and innovation in organizations', Research in organizational behavior, vol. 10, no., pp. 123-167.

[2] Amabile, T. M., Hennessey, B. A., \& Grossman, B. S. 1986, 'Social influences on creativity: The effects of contracted-for reward', Journal of Personality and Social Psychology, 50(1), 14-23.

[3] Amabile, T.M. 1993, 'Motivational Synergy: Toward New Conceptualizations of Intrinsic and Extrinsic Motivation in the Workplace', Human Resource Management Review, 3, 185-201

[4] Amabile, T. M. 1996, 'Creativity in context. Boulder, CO': Westview.

[5] Amabile, T. M., \& Pratt M. G. 2016, 'The Dynamic Componential Model of Creativity and Innovation in Organizations: Making Progress, Making Meaning', Research in Organizational Behavior, 36: 157-183

[6] Anderson, N., De Dreu, C. K. W., \& Nijstad, B. A. 2004, 'The routinization of innovation research: A constructively critical review of the state-of-the-science', Journal of Organizational Behavior, 25: 147-173.

[7] Anderson, N., Potočnik, K., \& Zhou, J. 2014, 'Innovation and creativity in organizations a state-of-the-science review, prospective commentary, and guiding framework', Journal of Management, 40, 1297-1333.

[8] Augur, P., Woodman, R. W. 2016, 'Creativity and Intrinsic Motivation: Exploring a Complex Relationship', The journal of applied behavioral science, Vol. 52, no.3, pp. $342-366$

[9] Baer, M., Oldham, G. R., \& Cummings, A. 2003, 'Rewarding creativity: When does it really matter?', The Leadership Quarterly, 14: 569-586.

[10] Deci, E. L. 1971, 'Effects of externally mediated rewards on intrinsic motivation', Journal of Personality and Social Psychology, 18(1), 105-115.

[11] Deci, E. L., \& Ryan, R. M. 1985, 'Intrinsic motivation and self-determination in human behavior', New York, Plenum.

[12] Dweck, C. S. 1986, 'Motivational processes affecting learning', American Psychologist, 41(10), 1040-1048. 
[13] Dweck, C. S. 1999, 'Essays in social psychology. Self-theories: Their role in motivation, personality, and development', New York, NY, US: Psychology Press.

[14] Eisenberger, R. 1992, 'Learned industriousness', Psychological Review, 99(2), 248267.

[15] Eisenberger, R., \& Selbst, M. 1994, 'Does reward increase or decrease creativity?', Journal of Personality and Social Psychology, 66(6), 1116-1127

[16] Eisenberger, R., \& Armeli, S. 1997, 'Can salient reward increase creative performance without reducing intrinsic creative interest?' Journal of Personality and Social Psychology, 72, 652-663.

[17] Eisenberger, R., Armeli, S., \& Pretz, J. 1998, 'Can the promise of reward increase creativity?', Journal of Personality and Social Psychology, 74, 704-714.

[18] Eisenberger, R., \& Rhoades, L. 2001, 'Incremental effects of reward on creativity', Journal of Personality and Social Psychology, 81, 728-741.

[19] Eisenberger, R., \& Aselage, J. 2009, 'Incremental effects of reward on experienced performance pressure: Positive outcomes for intrinsic interest and creativity' Journal of Organizational Behavior, 30: 95-117.

[20] Eisenberger, R., \& Cameron, J. 1996, 'Detrimental effects of reward on creativity: reality or myth?' American Psychologist, 51, 1153-1166.

[21] Eric M. Anderman \& Martin L. Maehr. 1994, 'Motivation and Schooling in the Middle Grades', Review of Educational Research, Vol 64, no. 2, pp. 287 - 309

[22] Elliott, E. S., \& Dweck, C. S. 1988, 'Goals: An approach to motivation and achievement', Journal of Personality and Social Psychology, 54(1), 5-12.

[23] Elliott, E. S. 1999, 'Approach and avoidance motivation and achievement goals', Educational Psychologist 34(3):169-189

[24] Elliot, A. J., \& Church, M. A. 1997, 'A hierarchical model of approach and avoidance achievement motivation', Journal of Personality and Social Psychology, 72(1), 218232.

[25] Gagné, M., \& Deci, E. L. 2005, 'Self-determination theory and work motivation', Journal of Organizational Behavior, 26(4), 331-362.

[26] George, J. M., \& Zhou, J. 2002, 'Understanding when bad moods foster creativity and good ones don't: The role of context and clarity of feelings', Journal of Applied Psychology, 87: 687-697.

[27] Hennessey, B. A. 1989, 'The effects of extrinsic constraints on children's creativity while using a computer', Creativity Research Journal, 2, 151-168. 
[28] Janssen, O., \& Van Yperen, N. W. 2004, 'Employees' goal orientations, the quality of leader-member exchange, and the outcomes of job performance and job satisfaction', Academy of Management Journal, 47: 368-384.

[29] Joussemet, M., \& Koestner, R. 1999, 'Effect of expected rewards on children's creativity', Creativity Research Journal, 12, 231-239.

[30] Kaplan, A. \& Maehr, M.L. 2007, 'The Contributions and Prospects of Goal Orientation Theory', Educational Psychology Review 19:141-184

[31] Kruglanski, A. W., Friedman, I., \& Zeevi, G. 1971, 'The effects of extrinsic incentive on some qualitative aspects of task performance', Journal of Personality, 39, 606-617.

[32] Madjar, N., Oldham, G. R., \& Pratt, M. G. 2002, 'There's no place like home? The contributions of work and non-work creativity support to employees' creative performance', Academy of Management, 45(4), 757-767.

[33] Maehr, M. L., \& Nicholls, J. G. 1980, 'Culture and Achievement Motivation: A Second Look. In N. Warren (Ed.)', Studies in Cross-Cultural Psychology (Vol. 2, pp. 221-267). New York: Academic Press.

[34] Maehr, M. L. 1984, 'Meaning and Motivation: Toward a Theory of Personal Investment', Research on Motivation in Education, 1, 115-144.

[35] Mumford, M. D., \& Gustafson, S. B. 1988, 'Creativity syndrome: Integration, application, and innovation', Psychological Bulletin, 103, 27-43.

[36] Nicholls, J. G. 1984, 'Achievement motivation: Conceptions of ability, subjective experience, task choice, and performance', Psychological Review, 91(3), 328-346.

[37] Nonaka, I. 1991, 'The Knowledge Creating Company', Harvard Business Review, 69, 96-104

[38] Pintrich, P. R., Smith, D. A. F., Garcia, T., \& McKeachie, W. J. 1993, 'Reliabilty and predictive validity of the Motivated Strategies for Learning Questionnaire (MSLQ)', Educational and Psychological Measurement, 53, 801-813.

[39] Porter, L. W., \& Lawler, E. E. 1968, 'Managerial attitudes and performance', Homewood, III, R.D. Irwin.

[40] Ryan, R. and Deci, E. 2000, 'Intrinsic and Extrinsic Motivations: Classic Definitions and New Directions', Contemporary Educational Psychology, 25(1), pp.54-67.

[41] Shalley, C. E., Zhou, J., \& Oldham, G. R. 2004, 'The effects of personal and contextual characteristics on creativity: Where should we go from here?', Journal of Management, 30: 933-958.

[42] Timothy C. Urdan \& Martin L. Maehr. 1995, 'Beyond a Two-Goal Theory of Motivation and Achievement: A Case for Social Goals. Review of Educational Research'.Vol 65, No. 3, pp. 213 - 243 
[43] Woodman, R. W., Sawyer, J. E., \& Griffin, R. W. 1993, 'Toward a theory of organizational creativity', Academy of Management Review, 18: 293-321.

[44] Wu, C., Parker, S. K., \& De Jong, J. P. J. in press, 'Need for cognition as an antecedent of individual innovation behavior', Journal of Management. doi:10.1177/0149206311429862

[45] Zhou, J., \& Shalley, C. 2003, 'Research on employee creativity: A critical review and directions for future research. In J. J. Martocchio \& G. R. Ferris (Eds.)', Research in personnel and human resources management, vol. 22: 165-217. Oxford, England: Elsevier Science.

[46] Zhou, J., \& Shalley, C. E. 2010, 'Deepening our understanding of creativity in the workplace: A review of different approaches to creativity research. In S. Zedeck (Ed.)', APA handbook of industrial and organizational psychology, vol. 1: 275-302. Washington, DC: American Psychological Association. 